Provided for non-commercial research and education use. Not for reproduction, distribution or commercial use.

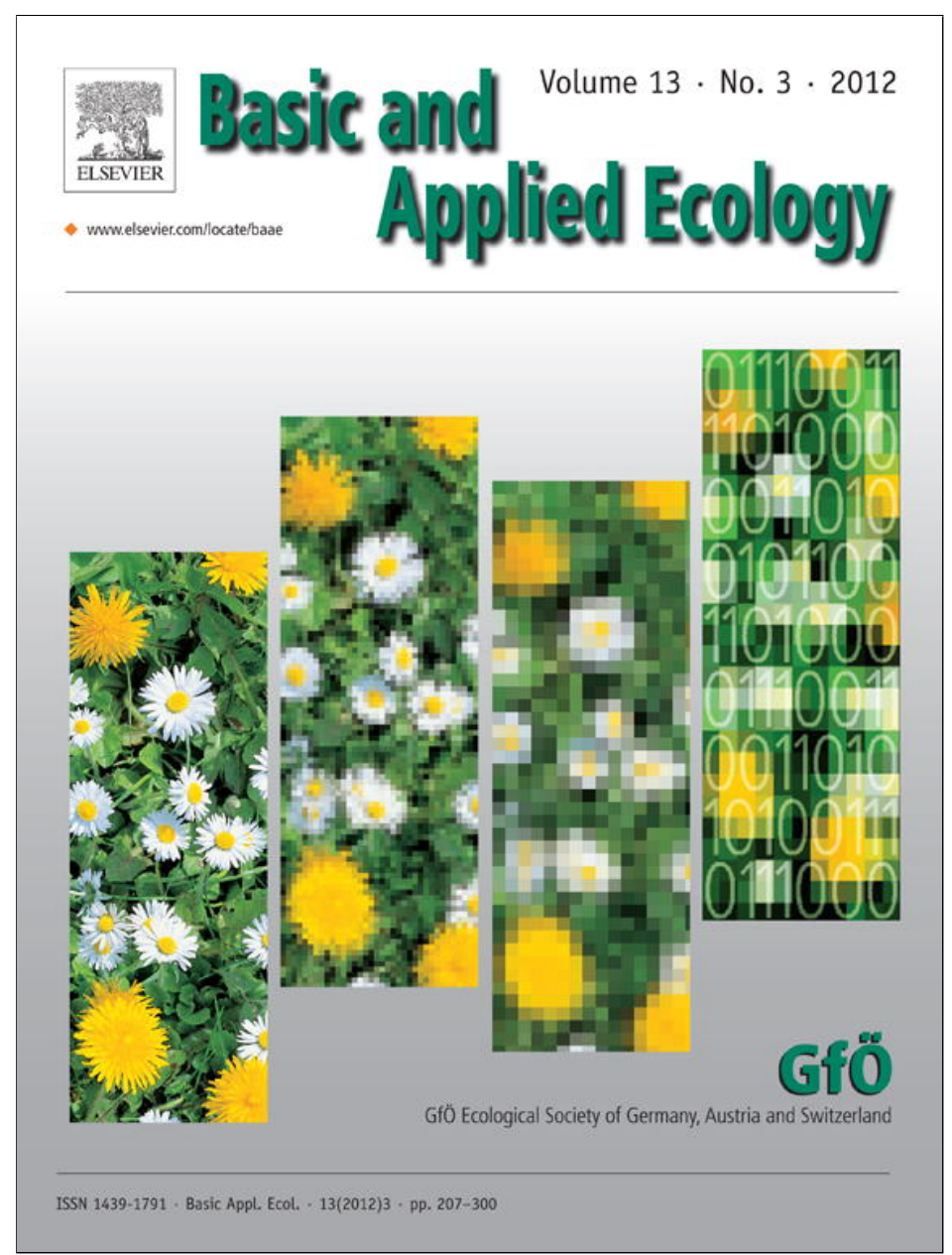

This article appeared in a journal published by Elsevier. The attached copy is furnished to the author for internal non-commercial research and education use, including for instruction at the authors institution and sharing with colleagues.

Other uses, including reproduction and distribution, or selling or licensing copies, or posting to personal, institutional or third party websites are prohibited.

In most cases authors are permitted to post their version of the article (e.g. in Word or Tex form) to their personal website or institutional repository. Authors requiring further information regarding Elsevier's archiving and manuscript policies are encouraged to visit:

http://www.elsevier.com/copyright 
 \\ Applied Ecology}

Basic and Applied Ecology 13 (2012) 241-249

www.elsevier.com/locate/baae

\title{
Performance of secondary parasitoids on chemically defended and undefended hosts
}

\author{
Saskya van Nouhuys ${ }^{a, b, *}$, Joanneke H. Reudler ${ }^{c}$, Arjen Biere ${ }^{d}$, Jeffery A. Harvey ${ }^{\mathrm{d}}$ \\ ${ }^{a}$ Department of Biological and Environmental Sciences, University of Helsinki, P.O. Box 65, FI-00014, Finland \\ ${ }^{\mathrm{b}}$ Cornell University, Department of Ecology and Evolutionary Biology, Corson Hall, Ithaca, NY 14853, USA \\ ${ }^{\mathrm{c}}$ Centre of Excellence in Evolutionary Research, Department of Biological and Environmental Sciences, University of Jyväskylä, P.O. Box 35, \\ FI-40014, Finland \\ ${ }^{\mathrm{d}}$ Department of Terrestrial Ecology, Netherlands Institute of Ecology, NIOO-KNAW, P.O. Box 50, NL-6700 AB Wageningen, The Netherlands
}

Received 14 November 2011; accepted 22 March 2012

\begin{abstract}
Defensive chemicals produced by plants can travel up the food chain by being sequestered by herbivores, and then in turn being sequestered by their parasitoids. Insect species with wide host ranges are predicted to perform poorly in the face of specific chemical defence. However, a species at a high trophic level is expected to have a wide host range. This creates a conflict for hyperparasitoids, many of which depend on specialized hosts. We studied the performance of two hyperparasitoids, Lysibia nana and Gelis agilis, both of which have wide host ranges, on two host species, one chemically defended and the other not. We predicted that both hyperparasitoids would perform better using the undefended host Cotesia glomerata than the defended host C. melitaearum, which sequesters terpenoid allelochemicals (iridoid glycosides). Furthermore, we expected that the progeny of G. agilis collected from an area where hosts defended by iridoid glycosides are absent (the Netherlands) would perform poorly using C. melitaearum in comparison with G. agilis collected from an area where C. melitaearum is a common host (Åland, Finland). In a series of laboratory experiments we found that, contrary to prediction, both hyperparasitoids performed well on both hosts, reaching a larger size on $C$. glomerata, but having a higher conversion efficiency and developing more quickly on the chemically defended C. melitaearum. Lysibia nana metabolized the plant derived iridoid glycosides, which are chemicals that it does not normally encounter. Gelis agilis retained some of the iridoid glycosides. But whereas Finnish G. agilis retained both aucubin and catalpol, Dutch G. agilis mainly retained aucubin, illustrating that though generalists, local populations still cope differently with toxic allelochemicals.
\end{abstract}

\section{Zusammenfassung}

Von Pflanzen synthetisierte chemische Abwehrstoffe können sich in der Nahrungskette anreichern, indem sie zunächst von Herbivoren und dann von deren Parasitoiden akkumuliert werden. Es wird angenommen, dass Insektenarten mit einem breiten Wirtsspektrum schlecht mit spezifischen chemischen Abwehrstoffen zurechtkommen. Arten in oberen Trophieebenen haben in der Regel ein breites Wirtsspektrum. Dadurch entsteht ein Konflikt für Hyperparasitoide, die häufig von einem spezialisierten Wirt abhängig sind. Wir haben zwei Hyperparasitoide mit breitem Wirtsspektrum, Lysibia nana und Gelis agilis, auf zwei Wirten untersucht. Einer der beiden Wirte unterliegt einer pflanzlichen chemischen Abwehr. Wir gingen davon aus, dass beide Hyperparasitoide besser auf dem Wirt, der keiner chemischen Abwehr unterliegt (Cotesia glomerata) zurechtkommen, als

\footnotetext{
*Corresponding author at: Department of Biological and Environmental Sciences, University of Helsinki, P.O. Box 65, FI-00014, Finland. Tel.: +3589191 57702; fax: +358919157694.

E-mail address: Saskya@ cornell.edu (S. van Nouhuys).
} 
auf C. melitaearum, welcher terpenoide Allelochemikalien (Iridoidglycoside) akkumuliert. Des Weiteren erwarteten wir, dass Nachkommen von G. agilis, entnommen aus einem Gebiet ohne Vorkommen von Wirten, die durch Iridoidglycoside verteidigt werden (Niederlande), schlechter mit C. melitaearum zurechtkommen, als G. agilis aus einem Gebiet, in dem C. melitaearum ein weit verbreiteter Wirt ist (Åland, Finnland). In mehreren experimentellen Studien im Labor zeigte sich, dass sich im Gegensatz zu unseren Vorhersagen beide Hyperparasitoide gut auf beiden Wirten entwickelten. Sie erreichten auf dem größeren Wirt, $C$. glomerata, eine größeren Biomasse, aber der ökologische Wirkungsgrad und die Entwicklungsgeschwindigkeit waren auf dem mit Iridoidglycosiden geschützten $C$. melitaearum, höher. Weiterhin zeigte sich, dass die pflanzlichen Iridoidglycoside durch Lysibia nana metabolisiert werden können, Chemikalien, denen sie normalerweise nicht begegnet. Gelis agilis akkumulierte einige der Iridoidglycoside. Individuen aus Finnland konnten sowohl Aucubin als auch Catalpol binden, während Individuen aus den Niederlanden nur Aucubin anreicherten. Dieses Ergebnis zeigt, dass auch lokale Populationen von Generalisten unterschiedlich mit giftigen Allelochemikalen zurechtkommen.

(C) 2012 Published by Elsevier GmbH on behalf of Gesellschaft für Ökologie.

Keywords: Allellochemical; Cotesia glomerata; Cotesia melitaearum; Gelis agilis; Host range; Hyperparasitoid; Iridoid glycoside; Lysibia nana; Multitrophic level interaction

\section{Introduction}

Defensive chemicals produced by plants travel up the food chain by being sequestered by herbivores. Sequestration of plant derived secondary chemicals can reduce predation of herbivores (Bowers 1991; Opitz \& Müller 2009). In some cases, these allelochemicals are further sequestered or concentrated by parasitoids of the herbivores, presumably aiding in their own defence (reviewed in Ode 2006). They may also be sequestered or concentrated beyond the third trophic level (Reudler et al. in prep), potentially providing defence for secondary parasitoids.

The effect of sequestered allelochemicals on consumers is thought to be related to their degree of host specialization. Species with wide host ranges are expected to perform poorly in the face of specific defensive chemicals because of the potentially great cost of maintaining multiple detoxification pathways (Bernays \& Graham 1988; Karban, Karban, Huntzinger, Pearse, \& Crutsinger 2010). We therefore generally think of defensive plant chemicals as effective against consumers with a wide host range, while consumers with a narrow host range overcome and may even benefit from them. This idea is well supported for consumers at the second trophic level (Barbosa et al. 1986; Bowers 1991; Stamp 2001). For consumers at higher trophic levels we have the same expectation, but there are few studies that have addressed associations between consumer host range, and effectiveness of specific defensive metabolites higher up the food chain.

Whether consumer species with wide host ranges indeed perform poorly on prey that sequester defensive compounds is likely to depend on consumer life style. Notably, the idea that higher trophic level generalists are deterred by plantderived chemicals sequestered by their hosts is well supported for predators (Montllor, Bernays, \& Cornelius 1991; Dyer \& Bowers 1996; Hristov \& Conner 2005; Baden \& Dobler 2009), but is less clear for endoparasitoids (Reudler, Biere, Harvey, \& van Nouhuys 2011). This may be because regardless of host range endoparasitoids have a more intimate physiological relationship with their prey than do predators, and thus must be better able to detoxify or avoid plantderived toxins (Ode 2006; Smilanich, Dyer, Chambers, \& Bowers 2009). It also may be that the association is not clear because we have little understanding of the host range of parasitoids (Shaw 1994). For instance, there is growing evidence that presumed generalist parasitoids are actually genetically differentiated populations or even cryptic species groups associated with particular host taxa (Kankare, Stefanescu, van Nouhuys, \& Shaw 2005; Smith et al. 2008; Kaartinen, Stone, Hearn, Lohse, \& Roslin 2010). Thus, parasitoid species, both primary and secondary, with nominally large host ranges may actually be locally specialized populations or cryptic species groups.

The restricted ability of generalist consumers to deal with sequestered specific allelochemicals in their prey is likely to pose an increasing challenge as we move up the trophic cascade. Insect species at high trophic levels, such as hyperparasitoids, are expected to have inherently wide host ranges because high on the food chain a single prey species is an unreliable resource (Holt \& Hochberg 1998; van Nouhuys 2005). This creates a conflict for hyperparasitoids, because many of them depend on a range of host species that may include specialized, chemically defended, hosts.

Based on these considerations, a general, but yet untested, prediction is that hyperparasitoids will perform poorly on those species from within their host range that are able to sequester allelochemicals, unless the hyperparasitoids represent aggregates of locally adapted populations specialized on different host species.

In this paper we test the prediction that hyperparasitoids perform poorly in terms of rate of parasitism, offspring development rate, and size, on host species from within their host range that sequester specific allelochemicals from lower trophic levels. We compare the performance of two hyperparasitoids, Gelis agilis (Fabricius) (Hymenoptera: Ichneumonidae) and Lysibia nana (Gravenhorst) (Hymenoptera: Ichneumonidae), both with a broad host range (though $G$. agilis uses a more diverse set of host species than does $L$. 
nana), on two congeneric parasitoid species. One of the host species is defended by sequestered allelochemicals, Cotesia melitaearum (Wilkinson) (Hymenoptera: Braconidae), and the other, C. glomerata (L.) (Hymenoptera: Braconidae) is not. The parasitoid $C$. melitaearum is specialized on the nymphalid butterfly Melitaea cinxia (L.) (Lepidoptera, Nymphalidae), whose larvae feed on plants containing a class of terpenoids known as iridoid glycosides (Wahlberg 2001). These compounds are sequestered by M. cinxia (Suomi, Siren, Jussila, Wiedmer, \& Riekkola 2002) and further sequestered or concentrated by C. melitaearum (Reudler et al. in prep). We hypothesize that the hyperparasitoids perform better on the undefended C. glomerata than on the defended C. melitaearum.

In addition, for one of the parasitoids, G. agilis, we investigate whether this species shows adaptation to local host chemical defence, despite its broad host range. Specifically we test whether individuals originating from an area where they use hosts sequestering iridoid glycosides (Finland, FI) perform better on iridoid glycoside-defended C. melitaearum than individuals originating from an area where they are unlikely to encounter such hosts (The Netherlands, NL). While such adaptive responses have been studied extensively in second trophic level consumers (herbivores), and in third trophic level species (predators and primary parasitoids), this study examines for the first time local responses to chemical defence at the fourth trophic level.

\section{Material and methods}

\section{Study species}

Hyperparasitoids - The parasitoid Lysibia nana is an ectoparasitoid of cocoons of Hymenoptera, particularly braconids in the subfamily Microgastrinae (Schwarz \& Shaw 2000). It has mostly been reared from gregarious species in the large genus Cotesia, and is closely associated with the host C. glomerata (Harvey, Wagenaar, \& Goles 2011). Lysibia nana is also known to use Cotesia parasitoids of iridoid glycoside feeding butterflies (Schwarz \& Shaw 2000; Stefanescu, Planas, \& Shaw 2009). However, in Finland where C. melitaearum is intensively studied, L. nana is not found to use C. melitaearum (Lei, Vikberg, Nieminen, \& Kuussaari 1997). Likewise, in the Netherlands the butterfly $M$. cinxia, on which C. melitaearum is specialized, is extinct and so $C$. melitaearum is absent. Further, other nymphalid butterflies that feed on iridoid glycoside producing Lamiales (Wahlberg 2001) are extremely rare in the Netherlands and absent from the collection area.

Gelis agilis is a broad generalist (Schwarz \& Shaw 1999), and a ubiquitous secondary parasitoid of Cotesia parasitoids of Lepidoptera larvae (Shaw, Stefanescu, \& van Nouhuys 2009; Stefanescu et al. 2009). Gelis agilis is solitary and the adults are entirely female, wingless and feed on both nectar and hosts (Schwarz \& Shaw 1999; Harvey 2008). In Finland there are multiple host species for G. agilis, including both $C$. melitaearum and C. glomerata (van Nouhuys \& Hanski 2000; van Nouhuys \& Tay 2001). By contrast, in the Netherlands, G. agilis has no recent evolutionary history using $C$. melitaearum or similar hosts for the same reasons as described for L. nana above. Where the two secondary parasitoids occur together, L. nana is sometimes itself used as a host by the more generalist G. agilis (Harvey, Wagenaar, \& Bezemer 2009; Stefanescu et al. 2009).

Parasitoids - The chemically defended host, C. melitaearum develops gregariously in the nymphalid butterfly $M$. cinxia which feeds on host plants defended with iridoid glycosides (Wahlberg 2001). Iridoid glycosides deter or inhibit generalist herbivores (Bowers 1991; Camara 1997; Biere, Marak, \& van Damme 2004; Harvey, van Nouhuys, $\&$ Biere 2005). However the specialist $M$. cinxia is adapted (Nieminen, Suomi, van Nouhuys, Sauri, \& Riekkola 2003; Harvey et al. 2005) and sequesters iridoid glycosides (Suomi et al. 2002). Recent work has shown that iridoid glycosides are further sequestered or concentrated by $C$. melitaearum (Reudler et al. in prep).

The chemically undefended host $C$. glomerata develops gregariously in Pieris butterfly (Lepidoptera: Pieridae) larvae that are specialized to feed on cruciferous plants containing glucosinolates as plant secondary compounds that inhibit generalist herbivores (Harvey 2008; Hopkins, van Dam, \& van Loon 2009; Shaw et al. 2009). Pieris butterflies do not sequester glucosinolates (Müller, Agerbirk, \& Olsen 2003). Therefore C. glomerata feeding on Pieris butterflies do not contain plant-derived glucosinolates.

\section{Insect rearing}

The L. nana cultures used for the experiments were obtained from wasps that emerged from $C$. glomerata cocoons attached to black mustard plants growing adjacent to the Netherlands Institute of Ecology at Wageningen, NL. The $L$. nana used for the experiment were then reared on cocoons of $C$. glomerata that were in turn hosted by Pieris brassicae caterpillars reared on cultivated cabbage plants $(\mathrm{CV}$ Cyrus) at the Institute of Ecology. All L. nana experiments were conducted in the Netherlands. For experiments involving the host $C$. melitaearum, freshly parasitized $M$. cinixa host caterpillars were sent from Finland.

The G. agilis cultures used for the experiments originated either from the Netherlands or from Finland. Dutch G. agilis were collected from $C$. glomerata cocoons attached to black mustard (Brassica nigra) plants near Heteren, NL. For the prior seven years they were reared on $C$. glomerata pupae hosted by Pieris brassicae caterpillars. Finnish G. agilis were obtained from $C$. melitaearum cocoons that had come from $M$. cinxia caterpillars collected from six local populations in Alland, FI, in the spring before the experiments were conducted. Upon adult eclosion, the wasps were allowed to host-feed and mature eggs for three days, after which they 
were given laboratory reared $C$. melitaearum cocoons, hosted by $M$. cinxia that had fed on Plantago lanceolata. To rear the G. agilis used for the experiments, individuals from both origins were given fresh $C$. glomerata cocoons for oviposition and host-feeding every other day for 10 days. After 15-18 days adult wasps from both origins began to eclose. These were host-fed using C. glomerata, and then maintained at $10^{\circ} \mathrm{C}$. Before use in an experiment, adult G. agilis were allowed to host-feed on a cluster of $C$. glomerata cocoons at room temperature $\left(22-25^{\circ} \mathrm{C}\right)$ for $24 \mathrm{~h}$ and had access to honey water (1:3). All G. agilis experiments were performed in Åland, Finland. For experiments involving the host $C$. glomerata, fresh $C$. glomerata pupae were sent from the Netherlands, and kept at $11^{\circ} \mathrm{C}$ until use.

\section{Set-up of the experiments}

We conducted two pairs of experiments. In the first two we studied whether the hyperparasitoids, L. nana (Exp. 1) and $G$. agilis (Exp. 2), performed differently in terms of rate of parasitism, offspring development rate and size, on the two host species $C$. glomerata and $C$. melitaearum. In the second pair of experiments we focused on one of the hyperparasitoids, $G$. agilis, studying whether those originating from the Netherlands (NL) and Finland (FI) performed differently on the two host species, C. glomerata (Exp. 3) and C. melitaearum (Exp. 4).

Experiment 1 - Comparison of the suitability of cocoons of the two host species $\boldsymbol{C}$. melitaearum and $\boldsymbol{C}$. glomerata for Lysibia nana. Approximately 110 C. glomerata and 74 C. melitaearum cocoons from multiple gregarious broods were teased apart and individually weighed on a microbalance (accuracy $1 \mathrm{mg}$ ). Cocoons of both C. glomerata and $C$. melitaearum were then individually presented to individual 5-10-day-old L. nana wasps for parasitism. At least 30 different individual wasps were used. Parasitism was verified by observation of insertion of the ovipositor. The exact time of parasitism was recorded, in order to get an accurate measure of egg to adult development time. This experiment was performed in the NIOO laboratory in Wageningen, NL.

Experiment 2 - Comparison of the suitability of cocoons of the two host species $C$. melitaearum and $C$. glomerata for Dutch $\boldsymbol{G}$. agilis. Cocoons of the host species were obtained as described above. For each replicate of the experiment, three Dutch G. agilis (10-20 days old) were placed with three individually weighed $\sim$ four-day-old $C$. melitaearum or $C$. glomerata cocoons in a $9 \mathrm{~cm}$ Petri dish for $24 \mathrm{~h}$. The experiment was replicated 44 times for each host species. Depending on the number of cocoons and wasps available, between four and eight replicates of each host species was run per day. Cotton wool soaked with honey water (1:3) was placed in each Petri dish for the wasps to drink. The number of cocoons provided to each wasp was based on the fecundity schedules of G. agilis described in
Harvey (2008). The G. agilis wasps were removed from the Petri dish after $24 \mathrm{~h}$. This experiment was performed in the laboratory in Finland.

Experiment 3 - Comparison of hyperparasitoid origins: Dutch and Finnish G. agilis on Cotesia glomerata cocoons. For each treatment replicate, two G. agilis females from the Netherlands or Finland were placed in a dish with three $C$. glomerata cocoons. This experiment was replicated 15 times for each wasp origin following the same procedure as described for experiment 2.

Experiment 4 - Comparison of hyperparasitoid origins: Dutch and Finnish G. agilis on Cotesia melitaearum cocoons. For each treatment replicate two G. agilis females from the Netherlands or Finland were placed in a dish with three C. melitaearum cocoons. This experiment was replicated 22 times for each wasp origin following the same procedure as described for experiment 2.

For all experiments the parasitized Cotesia pupae were left to develop at room temperature $\left(22-25^{\circ} \mathrm{C}\right)$ until egression of adult Cotesia and L. nana/G. agilis. If nothing emerged the cocoon was dissected. Adult L. nana/G. agilis were weighed within $4 \mathrm{~h}$ of emergence, and then frozen for later chemical analysis.

\section{Chemical analysis of iridoid glycoside content}

The iridoid glycoside content of G. agilis and L. nana progeny that egressed from $C$. melitaearum cocoons as well as the iridoid glycosides in the empty silken cocoons, which may be from either the host remains or the meconium of the hyperparasitoid. 38 G. agilis adults and cocoon remains from experiments 2 and 4 (26 NL and 12 FI) were each analyzed individually. 16 L. nana from experiment 1 were analyzed in groups of 2 . The samples were air dried and ground by hand in an Eppendorf tube. The wasps and their empty cocoons were extracted in $0.7 \mathrm{ml} 7 \% \mathrm{MeOH}$ and left overnight at room temperature. The crude extract was filtered on a $13 \mathrm{~mm}$ Syringe Filter w/0.2 $\mu \mathrm{m}$ PTFE membrane (VWR International). The concentrations of aucubin and catalpol were analyzed by HPLC using a Bio-LC (Dionex Corp., Sunnyvale, USA) equipped with a GS50 gradient pump, a CarboPac PA 20 guard $(3 \mathrm{~mm} \times 30 \mathrm{~mm})$ and analytical column $(3 \mathrm{~mm} \times 150 \mathrm{~mm})$. Detection was performed with an ED50 pulsed amperimetric detector (PAD) equipped with a disposable gold electrode using carbohydrate Waveform A (Dionex Corporation 1998). Isocratic flow of $70 \mathrm{mM} \mathrm{NaOH}$ (flow rate $0.25 \mathrm{ml} / \mathrm{min}$ ) was used for the elution. Columns were cleaned after each sample with alkaline (100 mM NaOH) $300 \mathrm{mM}$ sodium acetate solution. Retention times were $4.00 \mathrm{~min}$ and $6.08 \mathrm{~min}$ for aucubin and catalpol, respectively. Concentrations were analyzed using Chromeleon Client version 6.50 SP10a Build 1065 (Dionex Corp., Sunnyvale, USA). 


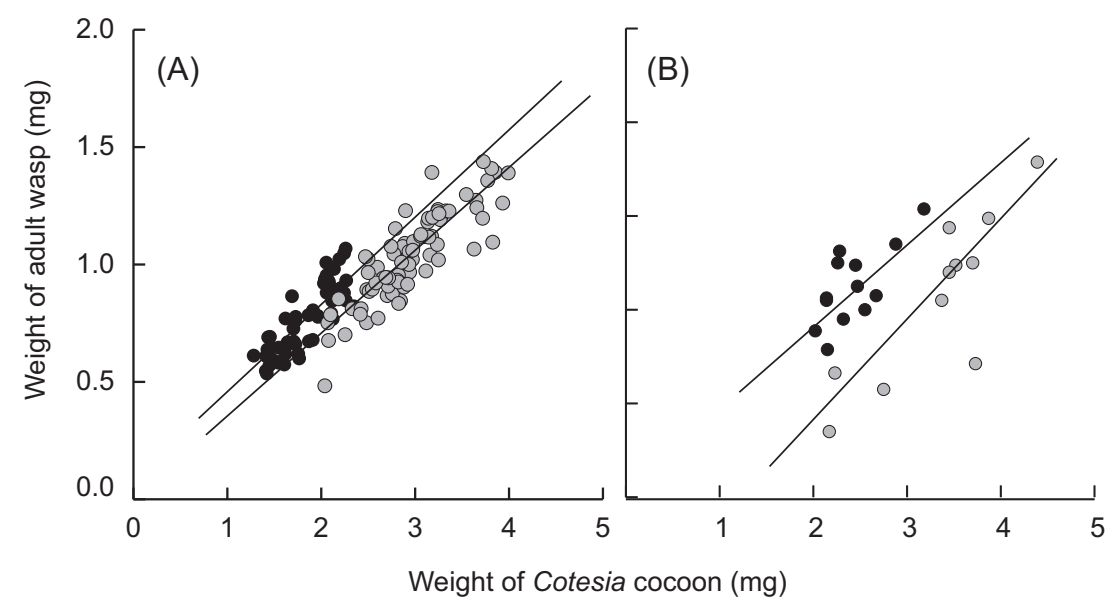

Fig. 1. Relationship between adult L. nana (A) (experiment 1) and Dutch G. agilis (B) (experiment 2) fresh body mass (mg), and cocoon mass (mg) of C. melitaearum (black circles) and C. glomerata (gray circles).

\section{Statistical analyses}

Each experiment was analyzed separately using the statistical software JMP (SAS Institute 2007). For experiment 1, two sided $t$-tests were used to compare weight and conversion efficiency (mg of hyperparasitoid adult produced per $\mathrm{mg}$ of host cocoon) between hosts for L. nana. A Fisher's exact test was used to analyse the rate of successful parasitism. For the G. agilis experiments (2-4) successful parasitism (production of an adult $G$. agilis) was analyzed using a GLM logit model with a binomial distribution. Date and replicate were included in the models along with host weight, host origin (Exp. 2) or G. agilis origin (Exp. 3 and 4). The effect of host species (Exp. 2) or G. agilis origin (Exp. 3 and 4) on development time and conversion efficiency were analysed using GLM with a normal distribution and maximum likelihood estimation. Host weight and the interaction between host weight and host species or G. agilis origin were included in the models. One-way ANOVA was used to analyze the association of $G$. agilis origin with iridoid glycoside content (\% dry weight catalpol, aucubin and total iridoid glycosides). Where means are presented in the text the value is followed by \pm 1 standard error.

\section{Results}

Experiment 1 - Comparison of the suitability of cocoons of the two host species $C$. melitaearum and $C$. glomerata for Lysibia nana.

All of the Cotesia cocoons were observed to be parasitized by $L$. nana. Parasitism was mostly successful and the rate of parasitism did not differ between the two host species (Fisher's exact test $p=0.31)$. Overall, 86\% (94/109) of the cocoons of C. glomerata produced L. nana and $78 \%$ (59 out of 74) cocoons of C. melitaearum produced L. nana. Cotesia melitaearum were smaller hosts than C. glomerata (on average $1.90 \mathrm{mg}$ vs. $3.00 \mathrm{mg} ; t=15.33, p<0.0001$ ) and $L$. nana developing on $C$. melitaearum were smaller than those developing on C. glomerata (on average $0.78 \mathrm{mg}$ vs. $1.05 \mathrm{mg}$; $t=8.96, p<0.0001$ ) (Fig. 1A). However, the efficiency of conversion was higher for C. melitaearum than for C. glomerata hosts; $L$. nana from $C$. melitaearum reached an average of 0.41 the weight of the host cocoon while L. nana from C. glomerata were on average only 0.35 the weight of the host cocoons ( $t=9.63, p<0.0001$; Fig. 2A). Furthermore, $L$. nana developed slightly faster on $C$. melitaearum than on C. glomerata, maturing, on average in 11.0 and 11.5 days, respectively $(t=7.41, p<0.0001$; Fig. $2 \mathrm{~B})$.

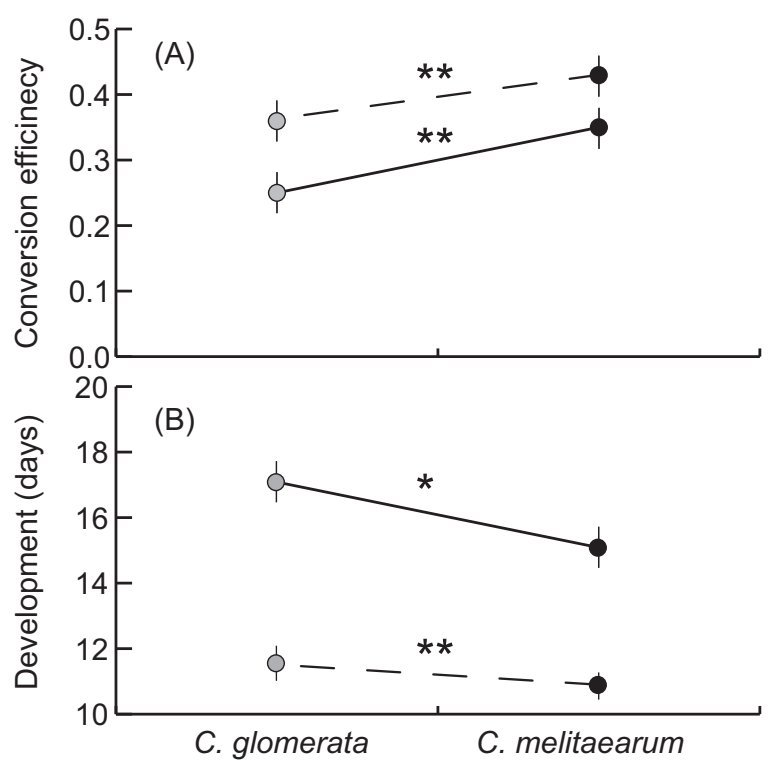

Fig. 2. The mean $( \pm \mathrm{SE})$ conversion efficiency (A) and rate of development (G. agilis wt/Cotesia wt) (B) of L. nana (dashed line, experiment 1) and Dutch G. agilis (solid line, experiment 2) on C. glomerata (gray circles) and C. melitaearum (black circles). $* p<0.0001, * * p<0.005$. 
Experiment 2 - Comparison of the suitability of cocoons of the two host species $C$. melitaearum and $C$. glomerata for Dutch G. agilis.

Out of the 264 cocoons (132 of each species), only 44 $(16.7 \%)$ were successfully parasitized by G. agilis. There was no significant difference in the rate of parasitism between the two host species, neither for those that made it to adulthood using C. glomerata or C. melitaearum (11 vs. 13), nor for those that were found fully developed but dead at dissection (12 vs. 8). Gelis agilis developed about 2 days faster on $C$. melitaearum than on C. glomerata (an average of 15 and 17 days, respectively; $\chi^{2}(1)=7.94 ; p=0.0048$; Fig. 2B). Cotesia melitaearum was also used more efficiently than $C$. glomerata. That is, G. agilis from C. melitaearum were 0.35 the mass of the host cocoon, whereas those from $C$. glomerata were 0.25 the mass of the host on average $\left(\chi^{2}(1)=7.94\right.$; $p<0.0001$; Fig. 2A). Consequently, though $C$. melitaearum cocoons are on average smaller than $C$. glomerata cocoons, G. agilis reached the same average mass, $0.85 \mathrm{mg}$, on both hosts (Fig. 1B).

Experiment 3 - Comparison of hyperparasitoid origins: Dutch and Finnish G. agilis on C. glomerata cocoons.

In this experiment $90 C$. glomerata cocoons were used, 22 (24.4\%) of which were successfully parasitized by G. agilis. $29 \%$ of cocoons offered to Finnish G. agilis were parasitized, and $20 \%$ of cocoons offered to Dutch G. agilis were parasitized. There was no difference in rate of parasitism between the two wasp origins, nor did G. agilis origin affect the development rate or efficiency of conversion $(0.30 \pm 0.32)$.

Experiment 4 - Comparison of hyperparasitoid origins: Dutch and Finnish $G$. agilis on $C$. melitaearum cocoons.

There were 132 C. melitaearum cocoons in this experiment, $35(26.5 \%)$ of which were parasitized by G. agilis. Larger host cocoons were parasitized at a higher rate than smaller host cocoons, with parasitized cocoons weighting $2.56 \pm 0.07 \mathrm{mg}$, and unparasitized cocoons weighing $2.33 \pm 0.05 \mathrm{mg}$ on average $\left(\chi^{2}=5.91, p=0.01\right)$. There was no significant difference in the rate of successful parasitism (FI 30.3\% and NL 22.7\%), development time (14.86 \pm 0.27 days), size of G. agilis $(0.93 \pm 0.08 \mathrm{mg})$ or efficiency of conversion $(0.36 \pm 0.03)$ between the two G. agilis origins.

\section{Sequestration of iridoid glycosides from $C$. melitaearum}

Gelis agilis hyperparasitoids developing in C. melitaearum retained small but significant amounts of iridoid glycosides as adults. The pattern of retention differed between Finnish and Dutch G. agilis (Fig. 3). Gelis agilis from both origins retained similar amounts $(\sim 0.0020 \%$ dry wt $)$ of the iridoid glycoside aucubin. However, while Dutch G. agilis contained only trace amounts of catalpol, Finnish G. agilis retained an average of $0.0032 \pm 0.001 \%$ dry weight catalpol (Fig. 3A;

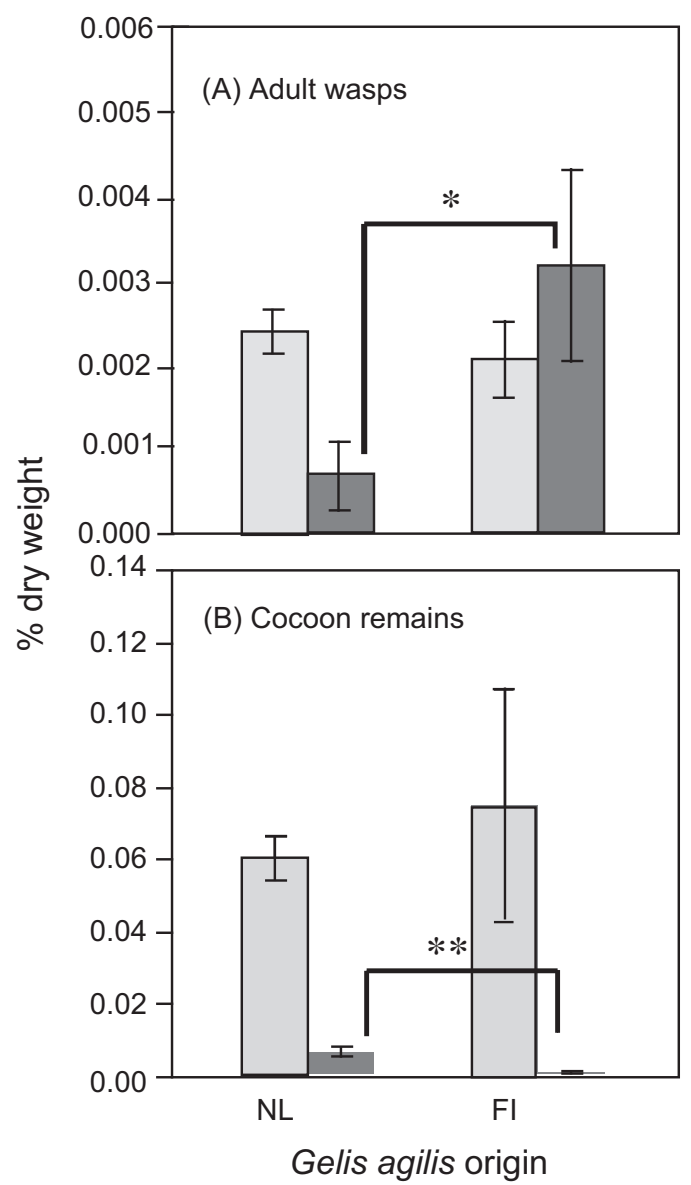

Fig. 3. The mean ( \pm SE) percent dry weight of the iridoid glycosides aucubin (light) and catalpol (dark) in Dutch and Finnish G. agilis adults (A) and remains of the $C$. melitaearum host after eclosion (B). $* t$-Ratio $=2.99, p=0.005$ ANOVA; $* * t$-ratio $=2.54, p=0.015$.

ANOVA $t$-ratio $(1,37)=2.99, p=0.005)$. Wasps from both origins left considerable amounts of aucubin $(\sim 0.06$ to $0.07 \%$ dry wt) in the remains of the host cocoon when they became adults (Fig. 3B), but left only small amounts of catalpol in the cocoon remains. Corresponding to the pattern in adult wasps, G. agilis of Finnish origin left less catalpol in cocoons than those of Dutch origin (Fig. 3B; ANOVA $t$-ratio $(1,37)=2.54$, $p=0.015)$.

In contrast to G. agilis, adult L. nana contained only trace amount of catalpol (0.00014-0.00039\% dry weight), and even less aucubin when developing in chemically defended C. melitaearum cocoons. The amounts of iridoid glycosides retained in adult $L$. nana were significantly lower than those retained in adult $G$. agilis, regardless of whether all wasps were compared $(F(1,44)=10.41, p=0.002)$ or whether only wasps from the same origin (NL) were included in the analy$\operatorname{ses}(F(1,32)=12.96, p=0.001)$. Lysibia nana also left little or no iridoid glycosides in the cocoon remains, with the exception of one out of the six cocoon samples in which $0.015 \%$ dry mass catalpol was detected. 


\section{Discussion}

We tested the hypothesis that two secondary parasitoids, G. agilis and L. nana, both generalists, but the second primarily associated with hosts in the genus Cotesia, would perform better on the chemically undefended host $C$. glomerata than on the chemically defended host $C$. melitaearum. We also predicted that G. agilis from the Netherlands, where C. melitaearum and potential hosts associated with iridoid glycoside feeding caterpillars are absent, would be less successful using the host $C$. melitaearum than G. agilis from Finland, that commonly use $C$. melitaearum as a host. We evaluated the hyperparasitoids with respect to rate of successful parasitism, offspring development time, size, and conversion efficiency. We assume that for most parasitoids and hyperparasitoids, fast development is advantageous because it decreases vulnerability to predation and generation time, and that a larger size is associated with increased longevity, fecundity, and reproductive success (Quicke 1997; Ellers \& Jervis 2003; Harvey 2008; Joyce, Bernal, Vinson, \& Lomeli-Flores 2009). This study is the first, as far as we know, to have examined local responses to chemical defence at the fourth trophic level.

Contrary to our prediction, we found that the defended host $C$. melitaearum is not less suitable for development of either of the parasitoid species than the undefended C. glomerata. The rate of successful parasitism was equal on the two hosts. Both L. nana and G. agilis reached a greater size on $C$. glomerata, which is a bigger host. However, they both developed faster and had a higher conversion efficiency (measured as hyperparasitoid adult weight/host cocoon weight) on $C$. melitaearum. The high performance on $C$. melitaearum is especially surprising for $L$. nana, first because previous studies have shown that this species is especially well adapted to C. glomerata (Harvey et al. 2011), and second because, in the area from which it was collected, L. nana has no recent history with iridoid glycoside sequestering hosts. In fact, $L$. nana was much more successful than G. agilis on both host species.

The analyses of iridoid glycosides in the hyperparasitoids developing on $C$. melitaearum revealed some interesting results. Insects may excrete, metabolize or sequester iridoid glycosides (Opitz \& Müller 2009; Lindstedt, Reudler, Ihalainen, Lindström, \& Mappes 2010). HPLC analysis of the iridoid glycoside content of $L$. nana developing from $C$. melitaearum indicates that the iridoid glycosides from $C$. melitaearum were broken down in the gut (Bowers 1991; Dobler 2001) instead of being excreted unmetabolized or retained in the body. In contrast, G. agilis both retained iridoid glycosides as adults and left some in the host cocoon unmetabolized (as meconium), or in the host remains. In order to sequester iridoid glycosides an insect must isolate the ingested compounds from the gut glucosidases and transport them to the hemolymph or other body tissue by an unknown mechanism (Pankoke, Bowers, \& Dobler 2010). This mechanism probably comes at a cost (Smilanich et al. 2009; Lindstedt et al. 2010), but has evolved in many insect lineages (Dobler 2001), and may be adaptive (Harvey et al. 2005). The amount of iridoid glycosides experienced by $G$. agilis and $L$. nana is small since $C$. melitaearum cocoons contain on average about $0.04 \%$ dry weight iridoid glycosides (Reudler et al. in prep). It is even smaller in comparison to the amounts in host plants in Alland (on average about 3\% dry weight: Nieminen et al. 2003), and in the larvae of the host $M$. cinxia (1 to $3 \%$ dry weight: Suomi et al. 2002). It is possible that a higher concentration of iridoid glycosides would have a negative effect on these wasps.

The amount of iridoid glycosides retained by G. agilis adults is a small fraction of what is in the host. This amount of stored defensive chemicals may be small, but can still have ecological consequences (Lindstedt et al. 2010). Though the need for defence might be presumed to decrease at higher trophic levels, developing G. agilis potentially fall prey to tertiary parasitoids, adults may be prey to spiders and other arthropods, and for any animal there is the need for generalized defence against disease. Iridoid glycosides are associated with defence against all of these enemies in lower trophic level species (Theodoratus \& Bowers 1999; Biere et al., 2004; Reudler et al. 2011), and should function in the same way at higher trophic levels. Finnish G. agilis concentrated more of the iridoid glycoside catalpol than $\operatorname{did} G$. agilis from the Netherlands. Interestingly, catalpol has been found to be the more efficiently sequestered of the two iridoid glycosides (Bowers \& Collinge 1992; Camara 1997). It is also more deterrent to predators (Bowers \& Collinge 1992; Dyer \& Bowers 1996; Nieminen et al. 2003). While the consequence of the difference in metabolism of iridoid glycosides between the G. agilis origins is not known, it is notable that they cope differently with the chemical defence, and that those originating from an area where the chemically defended host is common, retain more catalpol than those that do not normally encounter iridoid glycosides.

While the host ranges of secondary parasitoids are not well known, it is generally thought that they have broad host ranges because a single host species is an unreliable resource at higher trophic levels (Holt \& Hochberg 1998; Brodeur 2000; van Nouhuys 2005). Thus, that a species with a wide host range should be sensitive to plant derived allelochemicals is at odds with the needs of a species living towards the terminal end of the food chain. Our results support the argument that these high trophic level species are able to use a range of host species. Although L. nana has mostly been reared from cocoons of $C$. glomerata and is very well suited to that host (Harvey 2008; Harvey et al. 2009, 2011), records of other Cotesia host species in the field (Schwarz \& Shaw 2000; Stefanescue et al. 2009), and the suitability of C. congregata (Harvey, van Dam, Witjes, Soler, \& Gols 2007) and now $C$. melitaearum in the lab, suggest that it also possesses physiological mechanisms enabling it to face a potentially diverse array of chemical challenges. Gelis agilis is known from host records to be a ubiquitous generalist (Schwarz \& Shaw 1999). Here we show that though it can use a range of hosts, there is variation among populations in how the hosts 
are used. This variation is not based simply on the ability to parasitize available hosts, but rather in the metabolism of defensive chemicals.

\section{Acknowledgments}

We thank I. Merikanto, S. Ehonen and T. Lahtinen for laboratory assistance, the Ålands Naturbruksskola for laboratory facilities in Finland, and Klaus Hvvemeyer and two anonymous reviewers for helpful comments on the manuscript. Academic Academy of Finland grant nos. 213547 and 128508 provided financial support.

\section{References}

Baden, C. U., \& Dobler, S. (2009). Potential benefits of iridoid glycoside sequestration in Longitarsus melanocephalus (Coleoptera, Chrysomelidae). Basic and Applied Ecology, 10, 27-33.

Barbosa, P., Saunders, J. A., Kemper, J., Trumbule, R., Olechno, J., \& Martinatå, P. (1986). Plant allelochemicals and insect parasitoids effects of nicotine on Cotesia congregata (say) (Hymenoptera: Braconidae) and Hyposoter annulipes (Cresson) (Hymenoptera: Ichneumonidae). Journal of Chemical Ecology, 12, 1319-1327.

Bernays, E. A., \& Graham, M. (1988). On the evolution of host specificity in phytophagous arthropods. Ecology, 69, 886-892.

Biere, A., Marak, H. B., \& van Damme, J. M. M. (2004). Plant chemical defense against herbivores and pathogens: Generalized defense or trade-offs? Oecologia, 140, 430-441.

Bowers, M. D. (1991). Iridoid glycosides. In W. I. Taylor, \& A. R. Battersby (Eds.), Herbivores: Their interactions with plant secondary metabolites (pp. 297-325). Florida: Academic Press.

Bowers, M. D., \& Collinge, S. K. (1992). Fate of iridoid glycosides in different life stages of the buckeye, Junonia coenia (Lepidoptera: Nymphalidae). Journal of Chemical Ecology, 18, 817-831.

Brodeur, J. (2000). Host specificity and trophic relationships of hyperparasitoids. In M. E. Hochberg, \& A. R. Ives (Eds.), Parasitoid population biology (pp. 163-183). Princeton: Princeton University Press.

Camara, M. D. (1997). Physiological mechanisms underlying costs of chemical defense in Junonia coenia Hubner (Nymphalidae): A gravimetric and quantitative genetic analysis. Evolutionary Ecology, 11, 451-469.

Dionex Corporation. (1998). Technical note 21: Optimal settings for pulsed amperometric detection of carbohydrates using the Dionex ED40 electrochemical detector. Sunnyvale: Dionex Corporation.

Dobler, S. (2001). Evolutionary aspects of defense by recycled plant compounds in herbivorous insects. Basic and Applied Ecology, $2,15-26$.

Dyer, L. A, \& Bowers, M. D. (1996). The importance of sequestered iridoid glycosides as a defense against an ant predator. Journal of Chemical Ecology, 22, 1527-1539.

Ellers, J., \& Jervis, M. (2003). Body size and the timing of egg production in parasitoid wasps. Oikos, 102, 164-172.
Harvey, J. A. (2008). Comparing and contrasting development and reproductive strategies in the pupal hyperparasitoids Lysibia nana and Gelis agilis (Hymenoptera: Ichneumonidae). Evolutionary Ecology, 22, 153-166.

Harvey, J. A., van Dam, N. M., Witjes, L. M. A., Soler, R., \& Gols, R. (2007). Effects of dietary nicotine on the development of a herbivore, its parasitoid and secondary hyperparasitoid over four trophic levels. Ecological Entomology, 32, 15-23.

Harvey, J. A., van Nouhuys, S., \& Biere, A. (2005). Effects of quantitative variation in allelochemicals in Plantago lanceolata on development of a generalist and a specialist herbivore and their endoparasitoids. Journal of Chemical Ecology, 31, 287-302.

Harvey, J. A., Wagenaar, R., \& Bezemer, T. M. (2009). Lifehistory traits in closely related secondary parasitoids sharing the same primary parasitoid host: Evolutionary opportunities and constraints. Entomologia Experimentalis Et Applicata, 132, $155-164$.

Harvey, J. A., Wagenaar, R., \& Goles, R. (2011). Differing host exploitation efficiencies in two hyperparasitoids: When is a 'match made in heaven'? Journal of Insect Behavior, 24, 282-292.

Holt, R. D., \& Hochberg, M. E. (1998). The coexistence of competing parasites. II. Hyperparasitism and food chain dynamics. Journal of Theoretical Biology, 193, 485-495.

Hopkins, R. J., van Dam, N. M., \& van Loon, J. J. A. (2009). Role of glucosinolates in insect-plant relationships and multitrophic interactions. Annual Review of Entomology, 54, 57-83.

Hristov, N., \& Conner, W. E. (2005). Effectiveness of tiger moth (Lepidoptera, Arctiidae) chemical defenses against an insectivorous bat (Eptesicus fuscus). Chemoecology, 15, 105-113.

Joyce, A. L., Bernal, J. S., Vinson, S. B., \& Lomeli-Flores, R. (2009), Influence of adult size on mate choice in the solitary and gregarious parasitoids, Cotesia marginiventris and Cotesia flavipes. Journal of Insect Behavior, 22, 12-28.

Kaartinen, R., Stone, G. N., Hearn, J., Lohse, K., \& Roslin, T. (2010). Revealing secret liaisons: DNA barcoding changes our understanding of food webs. Ecological Entomology, 35, 623-638.

Kankare, M., Stefanescu, C., van Nouhuys, S., \& Shaw, M. R. (2005). Host specialization by Cotesia (Hymenoptera: Braconidae) species parasitizing rich assemblages of checkerspot (Melitaeine) butterflies in Spain. Biological Journal of the Linnaean Society, 86, 45-65.

Karban, R., Karban, C., Huntzinger, M., Pearse, I. A. N., \& Crutsinger, G. (2010). Diet mixing enhances the performance of a generalist caterpillar, Platyprepia virginalis. Ecological Entomology, 35, 92-99.

Lei, G. C., Vikberg, V., Nieminen, M., \& Kuussaari, M. (1997). The parasitoid complex attacking the Finnish populations of Glanville fritillary Melitaea cinxia (Lep: Nymphalidae), an endangered butterfly. Journal of Natural History, 31, 635-648.

Lindstedt, C., Reudler, J. H., Ihalainen, E., Lindström, L., \& Mappes, J. (2010). Diet quality affects warning coloration indirectly: Excretion costs in a generalist herbivore. Evolution, 64, 68-78.

Montllor, C. B., Bernays, E. A., \& Cornelius, M. L. (1991). Responses of two hymenopteran predators to surface chemistry of their prey: Significance for alkaloid-sequestering caterpillars. Journal of Chemical Ecology, 17, 391-399. 
Müller, C., Agerbirk, N., \& Olsen, E. C. (2003). Lack of sequestration of host plant glucosinolates in Pieris rapae and P. Brasicae. Chemoecology, 13, 47-54.

Nieminen, M., Suomi, J., van Nouhuys, S., Sauri, P., \& Riekkola, M. L. (2003). Effect of iridoid glycoside content on oviposition host plant choice and parasitism in a specialist herbivore. Journal of Chemical Ecology, 29, 823-844.

Ode, P. J. (2006). Plant chemistry and natural enemy fitness: Effects on herbivore and natural enemy interactions. Annual Review of Entomology, 51, 163-185.

Opitz, S. E. W., \& Müller, C. (2009). Plant chemistry and insect sequestration. Chemoecology, 19, 117-154.

Pankoke, H., Bowers, M. D., \& Dobler, S. (2010). Influence of iridoid glycoside containing host plants on midgut $B$-glucosidase activity in a polyphagous caterpillar, Spilosoma virginica Fabricius (Arctiidae). Journal of Insect Physiology, 56, 1907-1912.

Quicke, D. L. J. (1997). Parasitic wasps. London: Chapman and Hall.

Reudler, J. H., Biere, A., Harvey, J. A., \& van Nouhuys, S. (2011). Differential performance of a specialist and two generalist herbivores and their parasitoids on Plantago lanceolata. Journal of Chemical Ecology, 37, 765-778.

SAS Institute. (2007). JMP. Cary: SAS Institute, Inc.

Schwarz, M., \& Shaw, M. R. (1999). Western Palaearctic Cryptinae (Hymenoptera: Ichneumonidae) in the National Museums of Scotland, with nomenclatural changes, taxonomic notes, rearing records and special reference to the British check list. Part 2. Genus Gelis Thunberg (Phygadeuontini: Gelina). Entomologist's Gazette, 50, 117-125.

Schwarz, M., \& Shaw, M. R. (2000). Western Palaearctic Cryptinae (Hymenoptera: Ichneumonidae) in the National Museums of Scotland, with nomenclatural changes, taxonomic notes, rearing records and special reference to the British check list. Part 3. Tribe Phygadeuontini, subtribes Chiroticina, Acrolytina, Hemitelina and Gelina (excluding Gelis), with descriptions of new species. Entomologist's Gazette, 51, 147-186.

Shaw, M. R. (1994). Parasitoid host ranges. In B. A. Hawkins, \& W. Sheehan (Eds.), Parasitoid community ecology (pp. 111-144). Oxford: Oxford University Press.

Shaw, M. R., Stefanescu, C., \& van Nouhuys, S. (2009). Parasitoids of European butterflies. In J. Settele, T. G. Shreeve, M. Konvicka,
\& H. Van Dyck (Eds.), Ecology of butterflies in Europe (pp. 130-156). Cambridge: Cambridge University press.

Smilanich, A. M., Dyer, L. A., Chambers, J. Q., \& Bowers, M. D. (2009). Immunological cost of chemical defence and the evolution of herbivore diet breadth. Ecology Letters, 12, 612-621.

Smith, M. A., Rodriguez, J. J., Whitfield, J. B., Deans, A. R., Janzen, D. H., Hallwachs, W., et al. (2008). Extreme diversity of tropical parasitoid wasps exposed by iterative integration of natural history, DNA barcoding, morphology, and collections. Proceedings of the National Academy of Sciences of the United States of America, 105, 12359-12364.

Stamp, N. (2001). Enemy-free space via host plant chemistry and dispersion: Assessing the influence of tri-trophic interactions. Oecologia, 128, 153-163.

Stefanescu, C., Planas, J., \& Shaw, M. R. (2009). The parasitoid complex attacking coexisting Spanish populations of Euphydryas aurinia and Euphydryas desfontainii (Lepidoptera: Nymphalidae, Melitaeini). Journal of Natural History, 43, 553-568.

Suomi, J., Siren, H., Jussila, M., Wiedmer, S. K., \& Riekkola, M.L. (2002). Determination of iridoid glycosides in larvae and adults of butterfly Melitaea cinxia by partial filling micellar electrokinetic capillary chromatography, electrospray ionisation mass spectrometry. Analytical and Bioanalytical Chemistry, 376, 884-889.

Theodoratus, D. H., \& Bowers, M. D. (1999). Effects of sequestered iridoid glycosides on prey choice of the prairie wolf spider Lycosa carolinensis. Journal of Chemical Ecology, 25, 283-295. van Nouhuys, S. (2005). Effects of habitat fragmentation at different trophic levels in insect communities. Annales Zoologici Fennici, 42, 433-447.

van Nouhuys, S., \& Hanski, I. (2000). Apparent competition between parasitoids mediated by a shared hyperparasitoid. Ecology Letters, 3, 82-84.

van Nouhuys, S., \& Tay, W. T. (2001). Causes and consequences of small population size for a specialist parasitoid wasp. Oecologia, $128,126-133$

Wahlberg, N. (2001). The phylogenetics and biochemistry of host-plant specialization in Melitaeine butterflies (Lepidoptera: Nymphalidae). Evolution, 55, 522-537. 